\title{
Prognostic Role of 14F7 Mab Immunoreactivity against N-Glycolyl GM3 Ganglioside in Colon Cancer
}

\author{
Tania Lahera, ${ }^{1}$ Adanays Calvo, ${ }^{2}$ Griselda Torres, ${ }^{1}$ Charles E. Rengifo, ${ }^{3}$ \\ Santiago Quintero, ${ }^{4}$ María del Carmen Arango, ${ }^{1}$ Debora Danta, ${ }^{5}$ José M. Vázquez, ${ }^{5}$ \\ Xiomara Escobar, ${ }^{2}$ and Adriana Carr ${ }^{6}$ \\ ${ }^{1}$ Department of Basic Research and Immunology, National Institute of Oncology and Radiobiology, 29 and F Street Vedado, \\ 10400 Havana, Cuba \\ ${ }^{2}$ Department of Cell Biology and Tissues Banking, National Institute of Oncology and Radiobiology, 29 and F Street Vedado, \\ 10400 Havana, Cuba \\ ${ }^{3}$ Department of Pathology, Manuel Fajardo Hospital, Zapata and D Street Vedado, 10400 Havana, Cuba \\ ${ }^{4}$ Department of Pathology, National Institute of Oncology and Radiobiology, 29 and F Street Vedado, 10400 Havana, Cuba \\ ${ }^{5}$ Department of Surgery, National Institute of Oncology and Radiobiology, 29 and F Street Vedado, 10400 Havana, Cuba \\ ${ }^{6}$ Research and Development Direction, Center of Molecular Immunology, 216 Street and 15 Avenue Atabey, Playa, \\ P.O. Box 16040, 11600 Havana, Cuba
}

Correspondence should be addressed to Tania Lahera; tanialahera@infomed.sld.cu

Received 27 September 2013; Accepted 8 December 2013; Published 30 January 2014

Academic Editor: Thomas Rutherford

Copyright (C) 2014 Tania Lahera et al. This is an open access article distributed under the Creative Commons Attribution License, which permits unrestricted use, distribution, and reproduction in any medium, provided the original work is properly cited.

Purpose. To assess the prognostic role of 14F7 Mab immunoreactivity, against N-Glycolyl GM3 ganglioside, in patients with colon cancer (CC) and to evaluate the relationship between its expression and clinicopathological features. Methods. Paraffinembedded specimens were retrospectively collected from 50 patients with CC operated between 2004 and 2008. 14F7 Mab staining was determined by immunohistochemistry technique and its relation with survival and clinicopathologic features was evaluated. Results. The reactivity of 14F7 Mab was detected in all cases. Most cases had high level of immunostaining (70\%) that showed statistical correlation with TNM stage $(P=0.025)$. In univariate survival analysis, level of $14 \mathrm{~F} 7 \mathrm{Mab}$ immunoreactivity $(P=0.0078)$, TNM Stage $(P=0.0007)$ and lymphovascular invasion $(0.027)$ were significant prognostic factors for overall survival. Among these variables, level of $14 \mathrm{~F} 7 \mathrm{Mab}$ immunoreactivity $(\mathrm{HR}=0.268 ; 95 \% \mathrm{CI} 0.078-0.920 ; P=0.036)$ and TNM stage $(\mathrm{HR}=0.249 ; 95 \% \mathrm{CI} 0.066-0.932 ; P=0.039)$ were independent prognostic factors on multivariate analysis. Conclusions. This study is the first approach on the prognostic significance of 14F7 Mab immunoreactivity in patients with colon adenocarcinoma and this assessment might be used in the prognostic estimate of CC, although further studies will be required to validate these findings.

\section{Introduction}

Colon cancer (CC) is the third most common cancer in both genders worldwide and the second cause of cancer-related death in western countries, only overcome by lung cancer $[1,2]$. In Cuba, CC is one of the most frequent tumors and the third cause of death by cancer in both men and women [3].

Despite the significant advances in the treatment and knowledge of the colon tumor biology over the last decade, the 5-year survival after surgery varies from $90 \%$ to $10 \%$, depending on stage and progression of disease $[2,4]$. Therefore, it is important to increase our understanding of the molecular changes leading to development, spread, and metastasis and to identify potential prognostic and predictive markers for the disease.

To date, TNM (tumor-node metastasis) staging, based on the American Joint Committee on Cancer (AJCC) and the International Union against Cancer (UICC) classifications, has been the most important prognostic marker in CC [5]. 
However, this classification provides limited information, since cancer outcomes vary significantly among patients within the same stage. Therefore, numerous biomarkers have been investigated over the past years [6]. In this regard, ganglioside is one of the molecules under evaluation as biomarker and target for therapy [7].

Gangliosides are sialic acid-containing glycosphingolipids expressed in the plasmatic membrane of vertebrate's cell. N-Acetylneuraminic acid (NeuAc) is the most common in humans, while N-glycolylneuraminic acid (NeuGc) is not usually detected in normal tissues due to a specific inactivating mutation in the cytidine monophospho$\mathrm{N}$-acetylneuraminic acid hydroxylase (CMP-NeuAc hydroxylase) gene $[8,9]$. However, the expression of N-glycolylcontaining gangliosides has been found in a variety of human malignancies $[10,11]$, suggesting its possible role in oncogenic process and becoming in attractive targets for cancer immunotherapy.

The expressions of NeuGcGM3 ganglioside have been previously reported in different tumors using 14F7 Mab [1215], a murine IgG1 highly specific against the N-GlycolylGM3 ganglioside produced by the Center of Molecular Immunology, Havana, Cuba [10]. Blanco et al. evaluated the 14F7 Mab immunostaining in digestive system tumors, including some specimens of colon adenocarcinoma [16].

The objective of this study was to assess the prognostic role of 14F7 Mab immunoreactivity in patients with CC and evaluate the relationship between its expression and clinicopathological features.

\section{Materials and Methods}

2.1. Patients and Samples. We studied tumor specimens from 50 patients diagnosed with colon cancer who underwent tumor surgical resection at the National Institute of Oncology, Havana, Cuba, between 2004 and 2008. Tissues samples were processed following standard histological techniques described elsewhere [17].

All routinely stained sections were reviewed by two pathologists, who did all histopathologic classifications including stage, grade of differentiation, tumor type (mucinous or nonmucinous), peritumoral inflammation, degree of cell pleomorphism, and mitotic index; these last two were previously described [14].

Clinical data were obtained by reviewing the patient records. This research was approved by the ethical committee of the institute.

2.2. Immunohistochemistry. Briefly, $4 \mu \mathrm{m}$ thick sections were cut from formalin-fixed and paraffin-embedded blocks of surgical specimens. Subsequently the sections were dewaxed in xylene and rehydrated through a graded series of ethanol. Endogenous peroxidase activity was inhibited by incubating the sections in $0.3 \%$ hydrogen peroxide in methanol for 10 minutes followed by Tris-buffered saline wash. Nonspecific labeling was blocked with bovine serum albumin for $30 \mathrm{~min}$. As primary antibody, we used the $14 \mathrm{~F} 7 \mathrm{Mab}$, a murine IgG1 highly specific against N-Glycolyl-GM3 ganglioside.
This antibody was produced by the Center of Molecular Immunology, Havana, Cuba [10]. Sections were incubated with 14F7 Mab $(12 \mu \mathrm{g} / \mathrm{mL})$ for 30 minutes at room temperature. Then a kit Universal Dako LSAB+System-HRP (code K0679, Dako, Denmark) was applied to all sections according to the manufacturer's recommendations. Finally, the sections were counterstained with Mayer's hematoxylin, dehydrated through ascending ethanols to xylene, and mounted with Eukitt (Kinder GmbH \& Co., Freiburg, Germany). As a negative control, the primary antibody was omitted and replaced with Tris-buffered saline. Breast carcinoma tissue was used as a positive control [10]. Both tumoral and normal tissue area surrounding were evaluated.

2.3. Evaluation of Immunostaining. Immunohistochemical results were evaluated according to proportion of stained cells and intensity of 14F7 Mab reactivity. The proportion of stained cells was graded on a scale of $0-3$ ( 0 , no staining; $1,1-$ $50 \% ; 2,51-75 \%$; and $3,76-100 \%)$. The staining intensity was graded on a scale of $0-3 ; 0$, no staining; 1 , weak staining; 2 , moderate staining; and 3, strong staining. Subsequently, an immunoreactive scoring (IRS) was obtained by multiplying the two previously mentioned parameters. The cutoff level of 14F7 immunostaining was defined as a dichotomous variable of low level (IRS $<6$ ) or high level (IRS $\geq 6$ ). All slides were assessed by two trained observers who did not have knowledge of clinical characteristics or outcomes.

2.4. Statistical Analysis. The relationships between 14F7 Mab immunoreactivity and clinicopathologic variables were analyzed using the chi-square test. Correlations were determined using Spearman's test.

Survival rates were estimated by the Kaplan-Meier method and compared with the log-rank test. For multivariate analyses, the Cox regression model was used to identify independent prognostic factors for overall survival (OS) and disease-free survival (DFS). The model included all variables to have significant prognostic value in univariate analysis (log-rank test).

OS was measured from the date of surgery to death for any cause or last follow-up and was calculated for all patients. DFS was measured from the date of surgery to the date of second cancer, locoregional recurrence, distant metastases, and death for any cause or last follow-up and was calculated in patients with disease stages I-III. All data on survival and disease-free survival were updated in July 2013. The median follow-up time was 62 months.

A $P$ value $<0.05$ was considered statistically significant. Statistical analysis was carried out using SPSS (version 11.5; SPSS Inc., Chicago, IL).

\section{Results}

3.1. Patient Characteristics. Clinical and pathological characteristics of patients are summarized in Table 1. The study population had a median age of 63 years (range: $36-85$ years). 
TABLE 1: Clinicopathologic features of studied patients with colon cancer.

\begin{tabular}{|c|c|}
\hline Clinicopathologic features & Number (\%) \\
\hline \multicolumn{2}{|l|}{ Age, years $(n=47)$} \\
\hline$\leq 60$ & $20(42,6)$ \\
\hline$>60$ & $27(57,4)$ \\
\hline \multicolumn{2}{|l|}{$\operatorname{Sex}(n=50)$} \\
\hline Women & $27(54)$ \\
\hline Men & $23(46)$ \\
\hline \multicolumn{2}{|l|}{ Tumor location $(n=49)$} \\
\hline Sigmoid colon & $21(42,9)$ \\
\hline Left side colon & $3(6,1)$ \\
\hline Transverse colon & $6(12,2)$ \\
\hline Right side colon & $19(38,8)$ \\
\hline \multicolumn{2}{|l|}{ TNM stage $(n=50)$} \\
\hline I & $11(22)$ \\
\hline II & $17(34)$ \\
\hline III & $7(14)$ \\
\hline IV & $15(30)$ \\
\hline \multicolumn{2}{|c|}{ Grade of differentiation $(n=50)$} \\
\hline Well & $12(24)$ \\
\hline Moderate & $31(62)$ \\
\hline Poor & $7(14)$ \\
\hline \multicolumn{2}{|l|}{ Mucinous type $(n=50)$} \\
\hline Yes & $13(26)$ \\
\hline No & $37(74)$ \\
\hline \multicolumn{2}{|l|}{ Mitotic index $(n=49)$} \\
\hline Low & $36(73,5)$ \\
\hline Moderate & $4(8,2)$ \\
\hline High & $9(18,4)$ \\
\hline \multicolumn{2}{|c|}{ Grade of cell pleomorphism $(n=49)$} \\
\hline Low & $21(42,9)$ \\
\hline Moderate & $27(55,1)$ \\
\hline High & $1(2)$ \\
\hline \multicolumn{2}{|c|}{ Peritumoral inflammation $(n=50)$} \\
\hline Low & $23(46)$ \\
\hline High & $27(54)$ \\
\hline \multicolumn{2}{|c|}{ Lymphovascular invasion $(n=50)$} \\
\hline Yes & $5(10)$ \\
\hline No & $45(90)$ \\
\hline
\end{tabular}

TNM: tumor node metastases.

According to histopathological type, all tumors were adenocarcinomas and the majority was of a moderate histological grade (62\%). Perineural invasion was detected in one patient.

3.2. 14F7 Mab Immunostaining. Representative images of 14F7 Mab immunoreactivity are illustrated in Figure 1. The immunostaining was observed in all cases, with variable intensity and proportion of stained cells. Most specimens had strong intensity (68\%) and more than $75 \%$ of positive cells $(62 \%)$ as shown in Table 2. A moderate correlation was found between percentage of positive tumor cells and staining intensity (Spearman's correlation coefficient 0,606;
$P=0,000)$. According to IRS, most cases showed high level of immunostaining (70\%). The reactivity was observed on both membrane and cytoplasm of tumor cells with a staining pattern finely granular. In a few cases (six specimens) a moderate immunoreactivity in normal tissue areas was detected.

3.3. Relation of 14F7 Mab Immunostaining with Clinicopathologic Variables. The relation of $14 \mathrm{~F} 7 \mathrm{Mab}$ immunostaining with clinicopathologic variables is shown in Table 3. No significant differences were observed with age, sex, tumor location, grade of differentiation, mucinous type, mitotic index, pleomorphism grade, peritumoral inflammation, or lymphovascular invasion. However, the level of immunoreactivity showed statistical correlation with TNM stage $(P$ $=0,025$ and Spearman $r=0,317)$. When cases were analyzed independently, according to intensity or extent of staining (data not shown), no significant associations with clinicopathologic features were noted, except for the positive relation between proportion of stained cells and TNM stage $(P=0,038)$.

3.4. Survival Analysis. In survival analysis, there was a significant difference in the 5-year OS rates between high and low 14F7 Mab immunostaining (40\% versus 86,7\%; $P=0,002)$. Furthermore, patients with high level of $14 \mathrm{~F} 7$ Mab immunoreactivity had significantly impaired 5-year DFS $(P=0,046)$ than those with low level $(60,9 \%$ versus $92,3 \%)$.

Kaplan-Meier curves are represented in Figure 2. Immunostaining was associated significantly with $\mathrm{OS}(P=$ $0,0078)$ while no significant relation was demonstrated with DFS, although a trend existed $(P=0,0745)$.

The results of univariate and multivariate survival analysis are summarized in Table 4. Univariate analysis showed that level of 14F7 Mab immunostaining ( $P=0,0078)$, TNM stage $(P=0,0007)$, and lymphovascular invasion $(0,027)$ were significant prognostic factors for OS. Among these variables, level of 14F7 Mab immunostaining ( $\mathrm{HR}=0,268 ; 95 \% \mathrm{CI}$ $0,078-0,920 ; P=0,036)$ and TNM stage ( $\mathrm{HR}=0,249 ; 95 \%$ CI $0,066-0,932 ; P=0,039)$ were independent prognostic factors on multivariate analysis. For DFS, tumor location was significant prognostic factor $(P=0,036)$ since patients with sigmoides tumor had poor survival. However, a trend existed for the level of 14F7 Mab immunostaining $(P=0,074)$. As only one variable was significant in univariate analysis, multivariate analysis was not performed.

\section{Discussion}

Given the limited impact of conventional factors in CC, it is necessary to identify new prognostic biomarkers that provide information concerning the natural history of this disease. The present study is the first to evaluate the prognostic significance of 14F7 Mab immunostainingin patients with colon adenocarcinoma.

The 14F7 Mab immunoreactivity, against NeuGcGM3, has been previously reported in some tumors including breast 


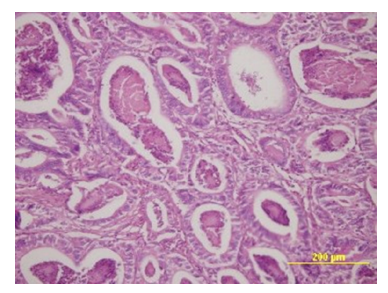

(a)

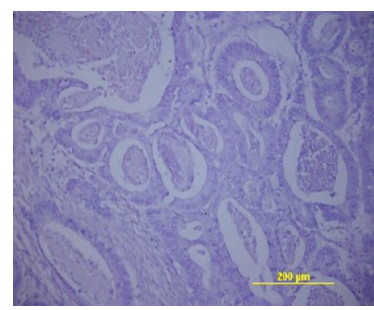

(c)

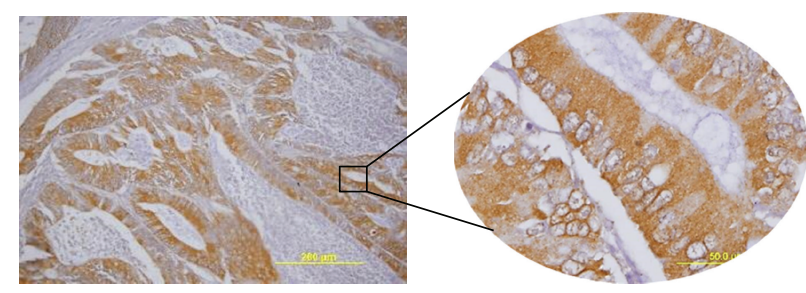

(b)

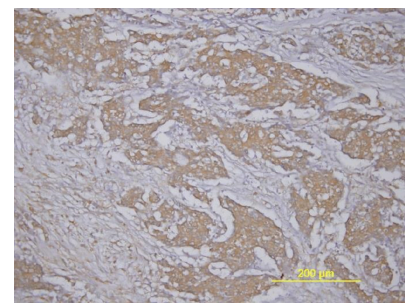

(d)

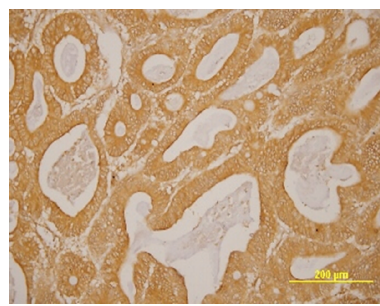

(e)

FIGURE 1: 14F7 Mab immunostaining in colon adenocarcinoma sections. (a) Hematoxylin and eosin staining. (b) 14F7 Mab positive reactivity in membrane and cytoplasm of tumor cells with finely granular pattern. (c) Negative control. (d) Low level of 14F7 Mab immunostaining. (e) High level of 14F7 Mab immunostaining. Original magnification 200x (inset 1000x magnification).

TABLE 2: 14F7 Mab immunostaining in colon cancer.

\begin{tabular}{lc}
\hline 14F7 Mab immunostaining $(n=50)$ & Number $(\%)$ \\
\hline Staining intensity & \\
$\quad$ Weak & $3(6)$ \\
$\quad$ Moderate & $13(26)$ \\
$\quad$ Strong & $34(68)$ \\
Staining extent (\%) & \\
$\quad-50 \%$ & $5(10)$ \\
$51-75 \%$ & $14(28)$ \\
$\quad+75 \%$ & $31(62)$ \\
Level of immunostaining & \\
$\quad$ Low (IRS $<6)$ & $15(30)$ \\
$\quad$ High $($ IRS $\geq 6)$ & $35(70)$ \\
\hline
\end{tabular}

IRS: immunoreactive score.

carcinoma [11], skin neoplasms [12], lung cancer [14], and neuroectodermal tumors [15].

In our research, we used formalin-fixed and paraffinembedded tissues, which is common in retrospective and long-term survival studies. However, as the routine tissues processing could damage the structure of gangliosides, further studies in frozen samples are recommended to confirm these results.

Although the presence of NeuGcGM3 in tumors has been demonstrated, the mechanisms that support its expression have been controversial. Some studies suggest that its presence in human cancer is due to metabolic incorporation of dietary NeuGc, related with changes in the metabolism of tumor cells. It is well described that cells can process exogenous sialic acids from the extracellular environment and use them for their own glycoconjugates $[18,19]$.
Furthermore, our data showed a moderate 14F7 Mab reaction in some normal glands surrounding the tumor. This is in line with previous studies that reported a limited recognition of 14F7 Mab in normal tissues [12-14, 16]. A possible mechanism for this finding is that normal eukaryotic cells were able to take in a portion of ingested NeuGc and process it for their own glycoconjugates [18, 20], although other researches are needed in this regard.

In this study, high 14F7 Mab immunostaining was significantly associated with advanced TNM stage $(P=0,025)$, which is characterized by the presence of cancer cells in regional lymph nodes and evidence for metastases. Although our findings suggest the role of NeuGcGM3 ganglioside in the oncogenic process, tumor growth and progression, further studies in larger sample with better distribution by each stage are required.

Our data is consistent with a previous report of Scursoni et al., who found a correlation between the expression of NeuGc-GM3, using 14F7 Mabs and more aggressive disease, in neuroectodermal tumors [15].

Previous studies have shown the relevance of this NeuGcGM3 in cancer progression and its capability of modulating CD4 expression on T cells [21-23]. Some properties of this ganglioside have been described including significant inhibition of human dendritic cells differentiation by inducing apoptosis in precursor cells [24], modification of CD4 expression [25], and promotion of Th2 differentiation pattern in T lymphocytes [26]. In fact, this molecule has been described as one of the most immunosuppressive gangliosides [27].

Other reports have studied a link between NeuGc expression and tumor progression [28]. Bardor et al. [18] and Nguyen et al. [29] showed that uptake of Neu5Gc into human tumor cells in vitro and delivery into the cytosolic compartment via a lysosomal transporter are enhanced by 
TABLE 3: 14F7 Mab immunostaining in relation to clinicopathologic features in colon cancer.

\begin{tabular}{|c|c|c|c|}
\hline \multirow{2}{*}{ Clinicopathologic features } & \multicolumn{3}{|c|}{ Level of immunostaining (IRS) } \\
\hline & Low & High & $P^{*}$ \\
\hline Age, years $(n=47)$ & & & 0,098 \\
\hline$\leq 60$ & 8 & 12 & \\
\hline$>60$ & 5 & 22 & \\
\hline $\operatorname{Sex}(n=50)$ & & & 0,596 \\
\hline Women & 8 & 19 & \\
\hline Men & 7 & 16 & \\
\hline Tumor location $(n=49)$ & & & 0,841 \\
\hline Sigmoid colon & 5 & 16 & \\
\hline Left side colon & 1 & 2 & \\
\hline Transverse colon & 2 & 4 & \\
\hline Right side colon & 7 & 12 & \\
\hline TNM stage $(n=50)$ & & & 0,025 \\
\hline I-II & 12 & 16 & \\
\hline III-IV & 3 & 19 & \\
\hline Grade of differentiation $(n=50)$ & & & 0,311 \\
\hline Well/moderate & 14 & 29 & \\
\hline Poor & 1 & 6 & \\
\hline Mucinous type $(n=50)$ & & & 0,602 \\
\hline Yes & 4 & 9 & \\
\hline No & 11 & 26 & \\
\hline Mitotic index $(n=49)$ & & & 0,550 \\
\hline Low & 10 & 26 & \\
\hline Moderate-high & 4 & 9 & \\
\hline $\begin{array}{l}\text { Grade of cell pleomorphism } \\
(n=49)\end{array}$ & & & 0,622 \\
\hline Low & 6 & 15 & \\
\hline Moderate-high & 8 & 20 & \\
\hline $\begin{array}{l}\text { Peritumoral inflammation } \\
(n=50)\end{array}$ & & & 0,596 \\
\hline Low & 7 & 16 & \\
\hline High & 8 & 19 & \\
\hline $\begin{array}{l}\text { Lymphovascular invasion } \\
(n=50)\end{array}$ & & & 0,524 \\
\hline Yes & 1 & 4 & \\
\hline No & 14 & 31 & \\
\hline
\end{tabular}

${ }^{*}$ Chi-square test; IRS: immunoreactive score; TNM: tumor node metastases. Bold value indicates statistical significance.

high cell growth rates. Furthermore, hypoxic conditions in tumors can upregulate expression of specific lysosomal transporter [30]. The tumor progression by stimulating inflammation via binding to Neu5Gc-positive tumor cells is another mechanism described. Hedlund et al. [31] found that the combination of tumor-associated Neu5Gc and circulating anti-Neu5Gc antibodies promotes tumor growth, by inducing weak inflammation, causing infiltration of inflammatory cells and enhanced angiogenesis.
In survival analysis, we reported that higher 14F7 Mab immunostaining was significantly associated with impaired OS (in univariate and multivariate analysis) and DFS (in univariate analysis), suggesting its potential use in the prognostic estimate of colon adenocarcinoma. No similar studies have been previously described in this regard.

Only few reports in lung cancer have evaluated the prognostic role of this molecule. Blanco et al. [14] and van Cruijsen et al. [28] found that NeuGc-GM3 expression was associated with better survival in non-small-cell lung cancer (NSCLC), while Hayashi et al. [32] shown an opposite data. Several factors can account for the controversial results. One possibility is the differences in predominant histological type, as in the first two cases was it squamous subtype, while in the third it was adenocarcinoma, resembling our study. Other factors like the number of patients evaluated and the distribution according to clinical stage as well as the specificity of the antibodies might lead to differences in results.

In current research, univariate survival analysis confirmed the poor OS associated with TNM stage and lymphovascular invasion, two putative pathologic markers of invasion and adverse outcome in CC [33].

Gangliosides have been considered attractive targets for cancer immunotherapy based on their higher abundance in tumors when compared with the corresponding normal tissue. In Cuba, two NeuGc ganglioside-based vaccines are currently tested. Several clinical trials have been performed with the anti-NeuGc-containing gangliosides anti-idiotype monoclonal antibody racotumomab (also known as 1E10) and the conjugated NeuGcGM3/VSSP (very small size proteoliposomes) nanoparticle vaccine for immunotherapy of melanoma, breast, and lung cancer. Both vaccines targeted to NeuGc-GM3 ganglioside have acceptable safety outcomes and are able to induce specific humoral and cellular immune responses. Preliminary evidence suggested that these vaccines may have a positive influence on survival in patients with immune response to NeuGcGM3 antigen [7, 34-36].

\section{Conclusion}

This study is the first approach on the prognostic significance of 14F7 Mab immunoreactivity, against N-Glycolyl GM3 ganglioside, in patients with colon adenocarcinoma. The immunostaining correlated significantly with TNM stage and it was an independent prognostic indicator of overall survival in multivariate survival analysis. The current research suggests that assessment of $14 \mathrm{~F} 7$ reactivity might be used in the prognostic estimate of colon adenocarcinoma, although our results need to be validated in a larger sample and prospective studies. Furthermore, the role of NeuGcGM3 in tumor biology and its differential expression in tumor cells suggest its potential use as target for immunotherapy.

\section{Conflict of Interests}

The authors indicated no potential conflict of interests. 
TABLE 4: Univariate and multivariate analysis of overall survival and disease-free survival in studied population.

\begin{tabular}{lccc}
\hline Variable & Univariate & Overall survival & \multicolumn{2}{c}{$\begin{array}{c}\text { Disease-free survival } \\
\text { Univariate } \\
\end{array}$} & $P$ & HR (95\% CI) & 0,117 \\
Age & 0,177 & & 0,269 \\
Sex & 0,551 & & $\mathbf{0 , 0 3 6}$ \\
Tumor location & 0,301 & $0,249(0,066-0,932)$ & $\mathbf{0 , 0 3 9}$ \\
TNM stage & $\mathbf{0 , 0 0 0 7}$ & & 0,879 \\
Grade of differentiation & 0,197 & & 0,412 \\
Mucinous type & 0,754 & & 0,326 \\
Mitotic index & 0,196 & 0,294 \\
Grade of cell pleomorphism & 0,425 & & 0,663 \\
Peritumoral inflammation & 0,9122 & 0,276 \\
Lymphovascular invasion & $\mathbf{0 , 0 2 7}$ & $0,315(0,087-1,146)$ & 0,080 \\
Level of 14F7 Mab immunostaining & $\mathbf{0 , 0 0 7 8}$ & $0,268(0,078-0,920)$ & $\mathbf{0 , 0 3 6}$ \\
\hline
\end{tabular}

HR: hazard ratio; CI: confidence interval; TNM: tumor node metastases. Bold value indicates statistical significance.

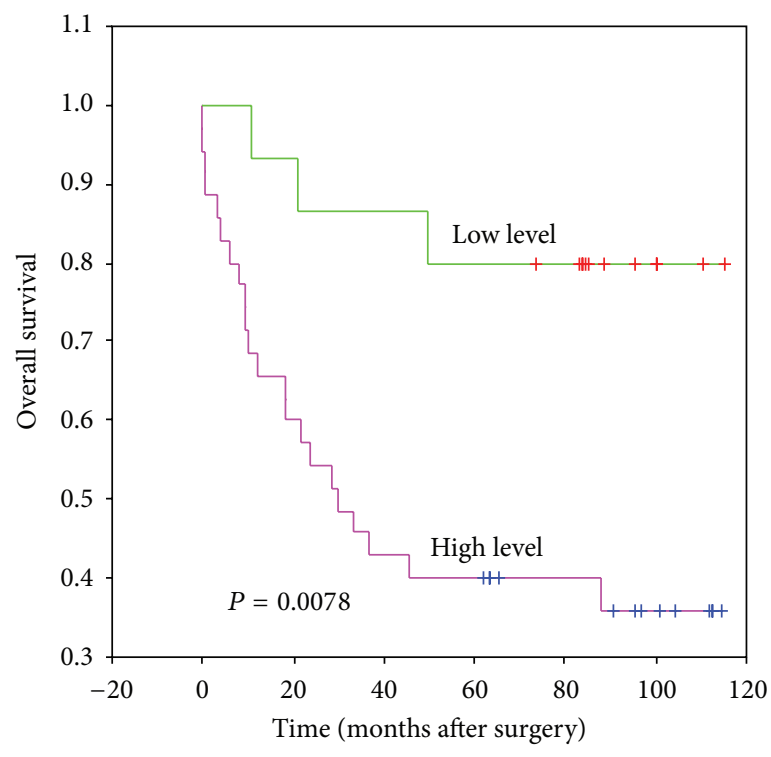

(a)

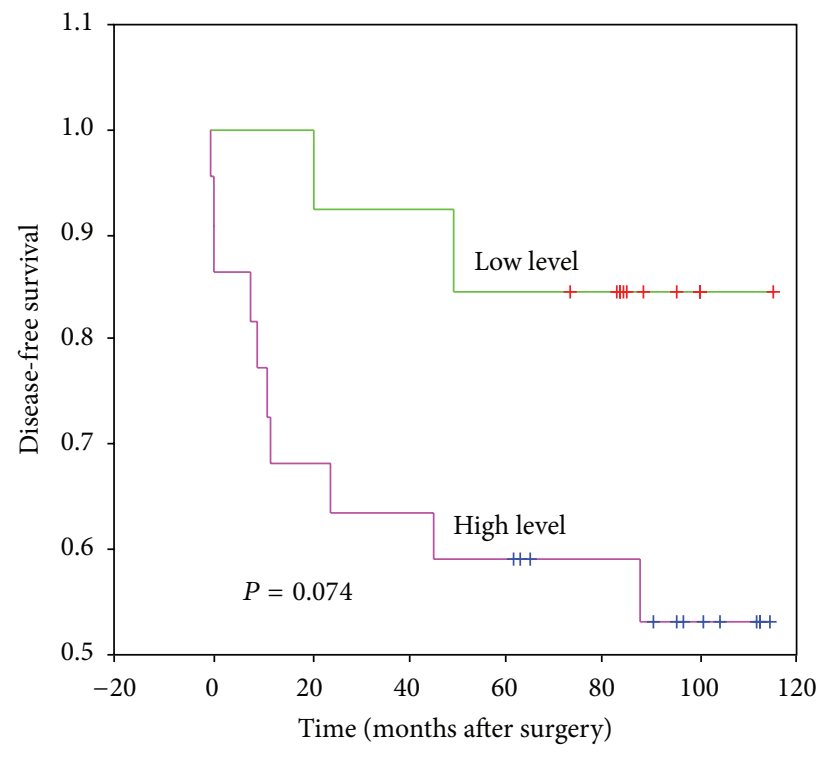

(b)

Figure 2: Kaplan-Meier curves for overall survival and disease-free survival according to 14F7 Mab immunostaining level. Statistical analysis by log-rank test.

\section{Acknowledgment}

The authors thank Rancés Blanco for the helpful comments of the paper.

\section{References}

[1] A. Jemal, R. Siegel, E. Ward et al., "Cancer statistics, 2008," CA Cancer Journal for Clinicians, vol. 58, no. 2, pp. 71-96, 2008.

[2] C. Grávalos, J. Maurel, F. Rivera, R. Salazar, I. Sevilla, and J. Sastre, "SEOM clinical guidelines for the adjuvant treatment of colorectal cancer," Clinical and Translational Oncology, vol. 12, pp. 724-728, 2010.
[3] Ministerio de Salud Pública de Cuba, Dirección Nacional de Estadísticas y Registros Médicos, Anuario Estadístico de Salud, 2012.

[4] I. Zlobec and A. Lugli, "Prognostic and predictive factors in colorectal cancer," Journal of Clinical Pathology, vol. 61, no. 5, pp. 561-569, 2008.

[5] G. Puppa, A. Sonzogni, R. Colombari, and G. Pelosi, “TNM staging system of colorectal carcinoma: a critical appraisal of challenging issues," Archives of Pathology and Laboratory Medicine, vol. 134, no. 6, pp. 837-852, 2010.

[6] V. Deschoolmeester, M. Baay, P. Specenier, F. Lardon, and J. B. Vermorken, "A review of the most promising biomarkers in colorectal cancer: one step closer to targeted therapy," Oncologist, vol. 15, no. 7, pp. 699-731, 2010. 
[7] D. F. Alonso, L. E. Fernandez, M. R. Gabri et al., "NGcGM3 ganglioside: a privileged target for cancer vaccines," Clinical and Developmental Immunology, vol. 2010, Article ID 814397, 8 pages, 2010.

[8] Y. N. Malykh, R. Schauer, and L. Shaw, "N-Glycolylneuraminic acid in human tumours," Biochimie, vol. 83, no. 7, pp. 623-634, 2001.

[9] A. Irie, S. Koyamat, Y. Kozutsumi, T. Kawasaki, and A. Suzuki, "The molecular basis for the absence of N-glycolylneuraminic acid in humans," Journal of Biological Chemistry, vol. 273, no. 25, pp. 15866-15871, 1998.

[10] A. Carr, A. Mullet, Z. Mazorra et al., "A mouse IgG1 monoclonal antibody specific for N-glycolyl GM3 ganglioside recognized breast and melanoma tumors," Hybridoma, vol. 19, no. 3, pp. 241-247, 2000.

[11] G. Marquina, H. Waki, L. E. Fernandez et al., "Gangliosides expressed in human breast cancer," Cancer Research, vol. 56, no. 22, pp. 5165-5171, 1996.

[12] R. Blanco, E. Rengifo, C. E. Rengifo, M. Cedeño, M. Frómeta, and A. Carr, "Immunohistochemical reactivity of the 14F7 monoclonal antibody raised against $\mathrm{N}$-glycolyl GM3 ganglioside in some benign and malignant skin neoplasms," ISRN Dermatology, vol. 2011, Article ID 848909, 8 pages, 2011.

[13] R. Blanco, M. Cedeño, X. Escobar et al., "Immunorecognition of the 14F7 Mab raised against N-Glycolyl GM3 ganglioside in some normal and malignant tissues from genitourinary system," ISRN Pathology, vol. 2011, Article ID 953803, 10 pages, 2011.

[14] R. Blanco, E. C. Rengifo, M. Cedeño, M. Frómeta, E. Rengifo, and A. Carr, "Immunoreactivity of the 14F7 Mab (raised against $\mathrm{N}$-glycolyl GM3 ganglioside) as a positive prognostic factor in non-small-cell lung cancer," Pathology Research International, vol. 2012, Article ID 235418, 12 pages, 2012.

[15] A. M. Scursoni, L. Galluzzo, S. Camarero et al., "Detection of N-glycolyl GM3 ganglioside in neuroectodermal tumors by immunohistochemistry: an attractive vaccine target for aggressive pediatric cancer," Clinical and Developmental Immunology, vol. 2011, Article ID 245181, 6 pages, 2011.

[16] R. Blanco, E. Rengifo, M. Cedeño, C. E. Rengifo, D. F. Alonso, and A. Carr, "Immunoreactivity of the 14F7 Mab raised against $\mathrm{N}-$ Glycolyl GM3 ganglioside in epithelial malignant tumors from digestive system," ISRN Gastroenterology, vol. 2011, Article ID 645641, 8 pages, 2011.

[17] J. A. Kiernan, Histological and Histochemical Methods. Theory and Practice, Cold Spring Harbor Laboratory Press, Oxford, UK , 4th edition, 2010.

[18] M. Bardor, D. H. Nguyen, S. Diaz, and A. Varki, "Mechanism of uptake and incorporation of the non-human sialic acid Nglycolylneuraminic acid into human cells," Journal of Biological Chemistry, vol. 280, no. 6, pp. 4228-4237, 2005.

[19] M. R. Gabri, L. L. Otero, D. E. Gomez, and D. F. Alonso, "Exogenous incorporation of neugc-rich mucin augments nglycolyl sialic acid content and promotes malignant phenotype in mouse tumor cell lines," Journal of Experimental and Clinical Cancer Research, vol. 28, no. 1, article 146, 2009.

[20] C. Oetke, S. Hinderlich, R. Brossmer, W. Reutter, M. Pawlita, and O. T. Keppler, "Evidence for efficient uptake and incorporation of sialic acid by eukaryotic cells," European Journal of Biochemistry, vol. 268, no. 16, pp. 4553-4561, 2001.

[21] S. Birklé, G. Zeng, L. Gao, R. K. Yu, and J. Aubry, "Role of tumorassociated gangliosides in cancer progression," Biochimie, vol. 85, no. 3-4, pp. 455-463, 2003.
[22] J. de Leòn, A. Fernández, C. Mesa, M. Clavel, and L. E. Fernández, "Role of tumour-associated N-glycolylated variant of GM3 ganglioside in cancer progression: effect over CD4 expression on T cells," Cancer Immunology, Immunotherapy, vol. 55, no. 4, pp. 443-450, 2006.

[23] J. de León, A. Fernández, M. Clavell et al., "Differential influence of the tumour-specific non-human sialic acid containing GM3 ganglioside on CD4+CD25-effector and naturally occurring CD4+CD25+ regulatory $\mathrm{T}$ cells function," International Immunology, vol. 20, no. 4, pp. 591-600, 2008.

[24] J. Péguet-Navarro, M. Sportouch, I. Popa, O. Berthier, D. Schmitt, and J. Portoukalian, "Gangliosides from human melanoma tumors impair dendritic cell differentiation from monocytes and induce their apoptosis," Journal of Immunology, vol. 170, no. 7, pp. 3488-3494, 2003.

[25] M. Sorice, A. Pavan, R. Misasi et al., "Monosialoganglioside GM3 inducesCD4 internalization in human peripheral blood $\mathrm{T}$ lymphocytes," Scandinavian Journal of Immunology, vol. 41, no. 2, pp. 148-156, 1995.

[26] F. A. Crespo, X. Sun, J. G. Cripps, and R. Fernandez-Botran, "The immunoregulatory effects of gangliosides involve immune deviation favoring type-2 T cell responses," Journal of Leukocyte Biology, vol. 79, no. 3, pp. 586-595, 2006.

[27] S. Ladisch, H. Becker, and L. Ulsh, "Immunosuppression by human gangliosides: I. Relationship of carbohydrate structure to the inhibition of T cell responses," Biochimica et Biophysica Acta, vol. 1125, no. 2, pp. 180-188, 1992.

[28] H. van Cruijsen, M. Ruiz, P. van der Valk, T. D. de Gruijl, and G. Giaccone, "Tissue micro array analysis of ganglioside Nglycolyl GM3 expression and signal transducer and activator of transcription (STAT)-3 activation in relation to dendritic cell infiltration and microvessel density in non-small cell lung cancer," BMC Cancer, vol. 9, article 180, 2009.

[29] D. H. Nguyen, P. Tangvoranuntakul, and A. Varki, "Effects of natural human antibodies against a nonhuman sialic acid that metabolically incorporates into activated and malignant immune cells," Journal of Immunology, vol. 175, no. 1, pp. 228 236, 2005.

[30] J. Yin, A. Hashimoto, M. Izawa et al., "Hypoxic culture induces expression of sialin, a sialic acid transporter, and cancerassociated gangliosides containing non-human sialic acid on human cancer cells," Cancer Research, vol. 66, no. 6, pp. 29372945, 2006.

[31] M. Hedlund, V. Padler-Karavani, N. M. Varki, and A. Varki, "Evidence for a human-specific mechanism for diet and antibody-mediated inflammation in carcinoma progression," Proceedings of the National Academy of Sciences of the United States of America, vol. 105, no. 48, pp. 18936-18941, 2008.

[32] N. Hayashi, H. Chiba, K. Kuronuma et al., "Detection of Nglycolyated gangliosides in non-small-cell lung cancer using GMR8 monoclonal antibody," Cancer Science, vol. 104, no. 1, pp. 43-47, 2013.

[33] P. Quirke and E. Morris, "Reporting colorectal cancer," Histopathology, vol. 50, no. 1, pp. 103-112, 2007.

[34] A. Carr, E. Rodríguez, M. D. C. Arango et al., "Immunotherapy of advanced breast cancer with a heterophilic ganglioside (NeuGcGM3) cancer vaccine," Journal of Clinical Oncology, vol. 21, no. 6, pp. 1015-1021, 2003.

[35] M. Alfonso, A. Díaz, A. M. Hernández et al., "An anti-idiotype vaccine elicits a specific response to $\mathrm{N}$-glycolyl sialic acid residues of glycoconjugates in melanoma patients," Journal of Immunology, vol. 168, no. 5, pp. 2523-2529, 2002. 
[36] S. Alfonso, R. M. Diaz, A. De La Torre et al., "1E10 antiidiotype vaccine in non-small cell lung cancer: experience in stage IIIb/IV patients," Cancer Biology and Therapy, vol. 6, no. 12, pp. 1847-1852, 2007. 


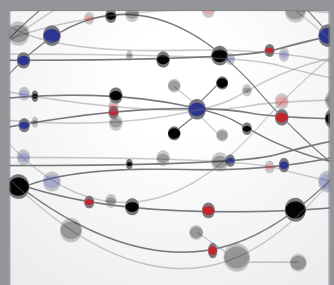

The Scientific World Journal
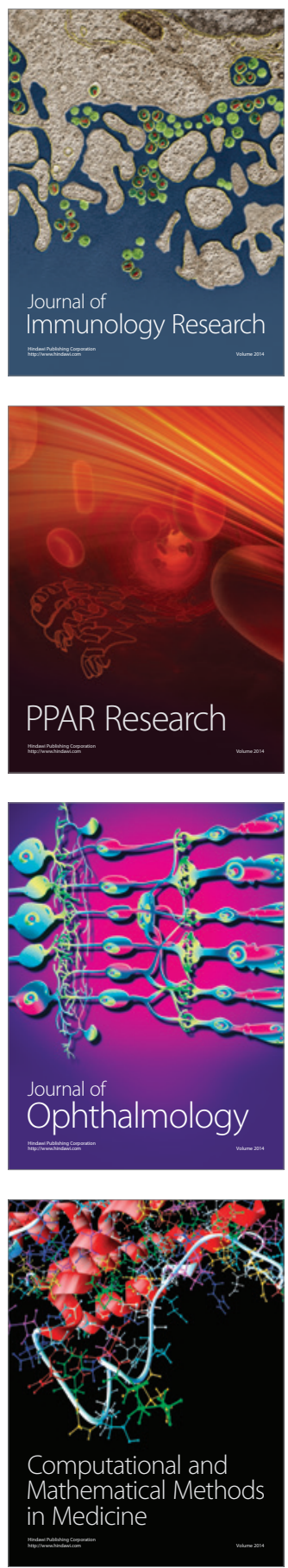

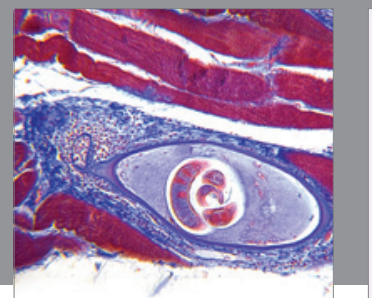

Gastroenterology

Research and Practice
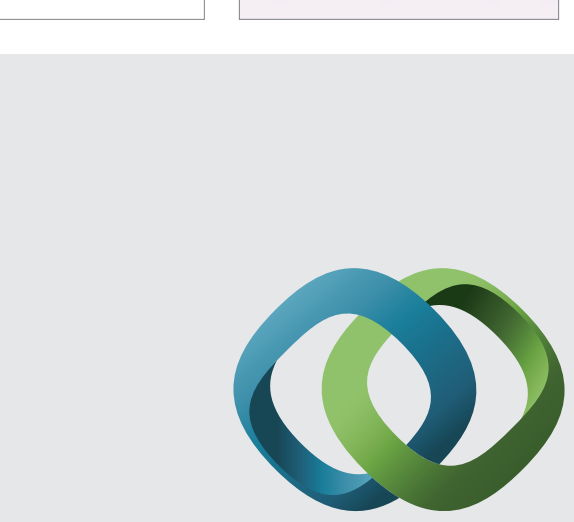

\section{Hindawi}

Submit your manuscripts at

http://www.hindawi.com
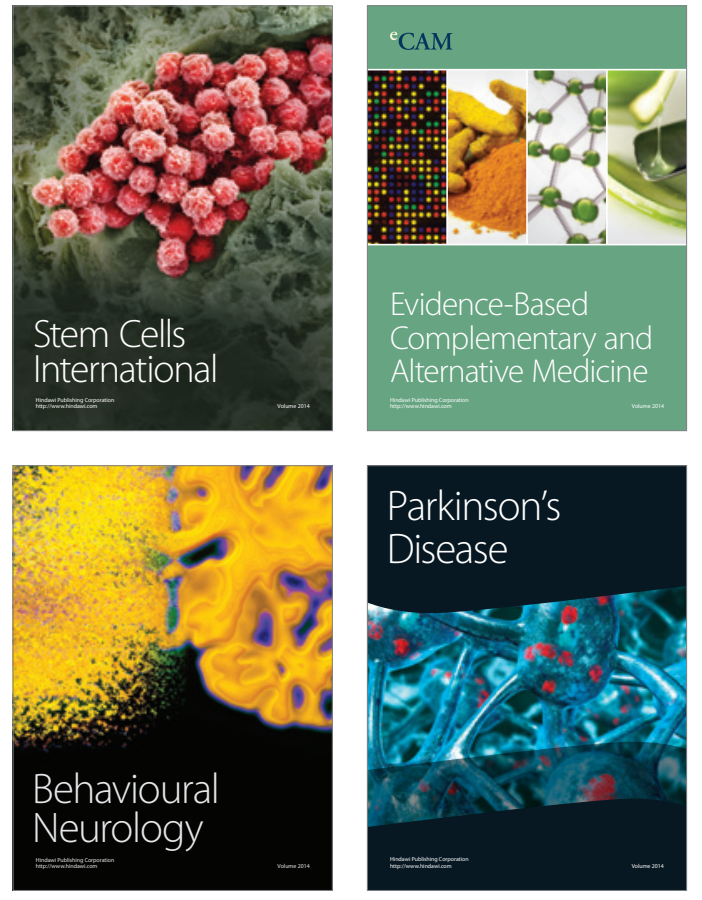
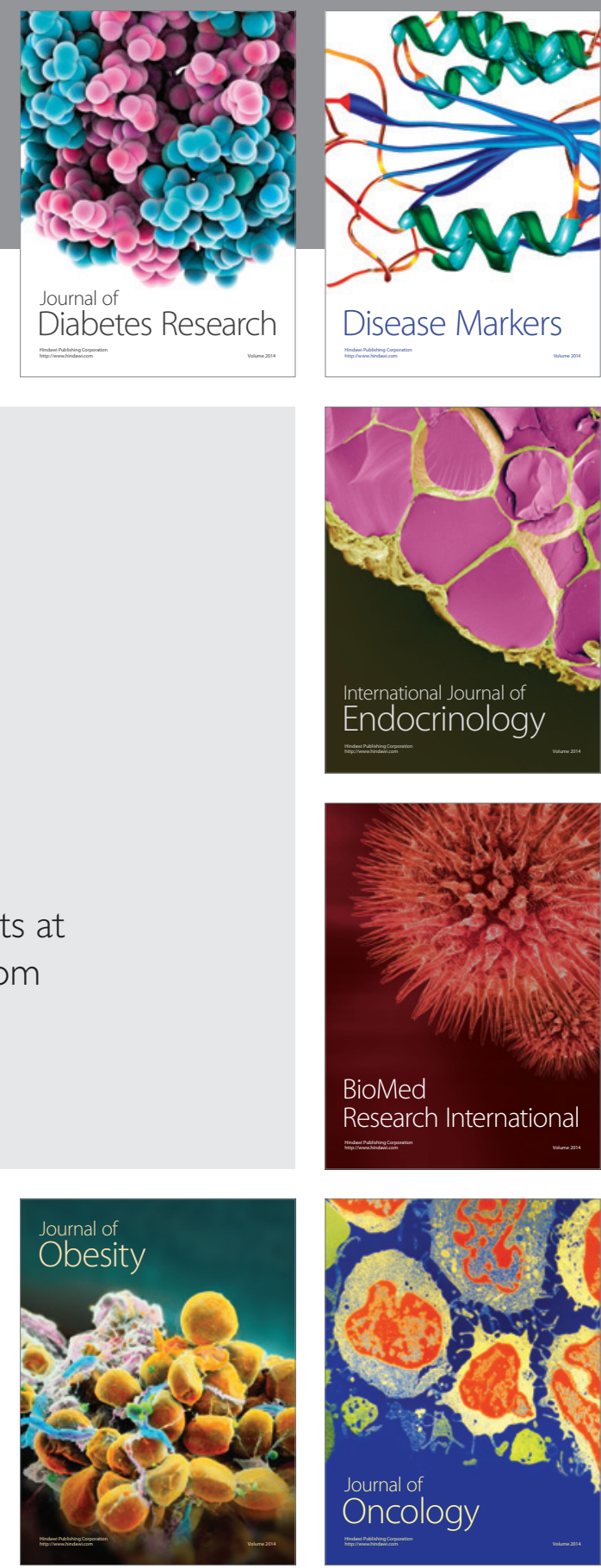

Disease Markers
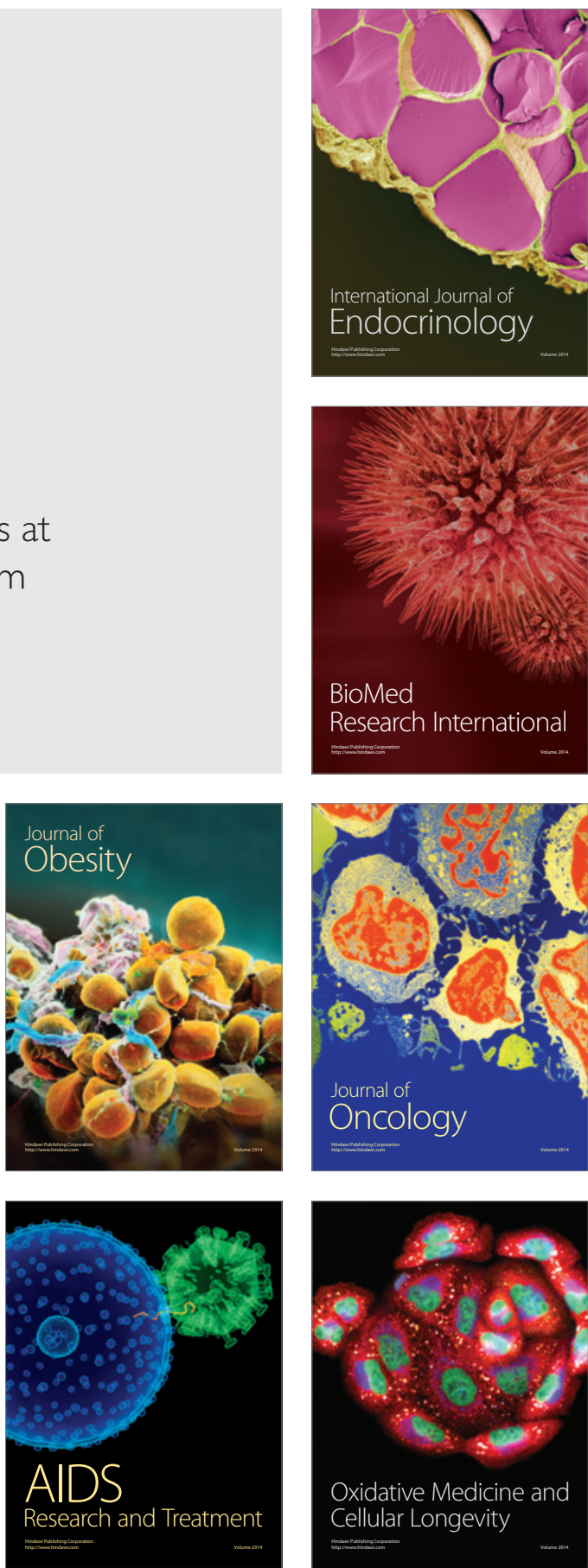